\title{
Optimalisasi Penjualan Motor Menggunakan Algoritma Particle Swarm Optimization (PSO)
}

\author{
Ujang Juhardi ${ }^{1}$, Andilala ${ }^{2}$ \\ ${ }^{1}$ Dosen Tetap Program Studi Teknik Informatika Fakultas Teknik Universitas Muhammadiyah Bengkulu \\ Alamat Jl. Bali (Telp. (0736) 22765, Fax. (0736) 26161; e-mail: ujangjuhardi@umb.ac.id) \\ ${ }^{2}$ Dosen Tetap Program Studi Sistem Informasi Fakultas Teknik Universitas Muhammadiyah Bengkulu \\ Alamat Jl. Bali (Telp. (0736) 22765, Fax. (0736) 26161; e-mail: andilala@umb.ac.id)
}

\begin{abstract}
Currently there are still many users of transportation, the vehicles needed to meet their daily needs never run out, many companies compete in the transportation sector, especially in the field of motorcycle sales. The research that will be carried out is to find out the results of increased motorcycle sales, help speed up the process of optimizing sales increases by using the Particle Swarm Optimization (PSO) algorithm. The conclusion of this research is to find out discounts and advances that will be used with the aim of increasing motorcycle sales in the future and a large estimate of total sales for the next 12 months.
\end{abstract}

Keyword: PSO, optimalisasi, SPK, Metode

Intisari- Saat ini pengguna transportasi masih banyak sekali, kendaraan-kendaraan yang dibutuhkan guna untuk memenuhi kebutuhan sehari-hari tidak pernah kunjung habis, banyak perusahaan-perusahaan yang bersaing dalam bidang transportasi terutama pada bidang penjualan motor. Penelitian yang akan dilakukan adalah untuk mengetahui hasil peningkatan penjualan motor, membantu mempercepat proses pengoptimalan peningkatan penjualan dengan menggunakan algoritma Particle Swarm Optimization (PSO). Kesimpulan dari penelitian ini adalah untuk mengetahui diskon dan uang muka yang akan digunakan dengan tujuan meningkatkan penjualan motor kedepan dan perkiraan besar total penjualan selama 12 bulan kedepan.

Kata kunci : PSO, optimalisasi, SPK, Metode

\section{PENDAhuluan}

Kendaraan-kendaraan yang dibutuhkan guna untuk memenuhi kebutuhan sehari-hari tidak pernah kunjung habis, banyak perusahaan-perusahaan yang bersaing dalam bidang transportasi terutama pada bidang penjualan moto, maka diperlukan upaya perusahaan agar tetap survive serta mampu bersaing secara global, dan upaya penting yang diperlukan mengikuti perkembangan perubahan yang terjadi secara mendadak dalam kondisi persaingan global.

Ditengah-tengah persaingan dan berkompetisi dalam pemasaran peningkatan penjualan sepeda motor digunakanlah cara peningkataan produktivitas, peningkatan produktivitas merupakan usaha sangat penting bagi perbaikan penggunaan sumber daya khususnya pada produktivitas produksi [1].

Untuk mengoptimalkan penjualan motor maka dilakukanlah optimalisasi penjualan motor untuk memperoleh keuntungan yang maksimal, optimalisasi efisiensi sangat dibutuhkan, salah satunya adalah kinerja dari seluruh komponen sistem yang ada dengan menciptakan suatu sistem yang terintegrasi antara yang satu dengan yang lainnya, dengan melahirkan suatu sistem yang handal [2].

Dengan demikian untuk mempermudah bersaing dan menciptakan suatu strategi maka dilakukanlah optimalisasi peningkatan penjualan motor menggunakan Algoritma Particle Swarm Optimization (PSO) yang diperkenalkan oleh Kennedy dan Eberhart pada tahun 1995, proses algoritmanya seperti sekumpulan burung dalam suatu swarm yang diinspirasi oleh perilaku sosial dari binatang, PSO adalah salah satu dari teknik komputasi evolusioner, yang mana populasi pada PSO didasarkan pada penelusuran algoritma dan diawali dengan suatu populasi yang random yang disebut dengan particle, berbeda dengan teknik komputasi evolusioner lainnya, setiap particle di dalam PSO juga berhubungan dengan suatu velocity, particle-particle mempunyai kecenderungan untuk bergerak ke area 
penelusuran yang lebih baik setelah melewati proses penelusuran [3].

\section{LANDASAN TEORI}

\section{A. Optimalisasi}

Adanya penanganan secara terkomputerisasi dengan membangun sebuah sistem informasi, yakni sistem informasi yang bertujuan mengoptimalkan sumberdaya yang ada, sehingga untuk mencapai efisiensi dan efektifitas counter tersebut. Optimalisasi efisiensi sangat dibutuhkan, salah satunya adalah kinerja dari seluruh komponen sistem yang ada dengan menciptakan suatu sistem yang terintegrasi antara yang satu dengan yang lainnya, dengan melahirkan suatu sistem yang handal, yaitu sistem informasi berbasis computer [2]

\section{B. Peningkatan penjualan}

Dengan pemasaran produk yang baik maka akan dapat meningkatkan penjualan dan merebut pangsa pasar. Jika itu sudah terjadi maka dapat dipastikan perusahaan akan mendapatkan laba yang maksimal. Jika pemasaran produk yang dilakukan tidak atau kurang tepat maka akan terjadi penurunan pendapatan yang diterima oleh perusahaan tersebut [4].

\section{Kompetisi Perusahaan}

Perkembangan ilmu pengetahuan dan teknologi yang semakin pesat menimbulkan suatu kondisi dimana perusahaan saling berkompetisi satu sama lain untuk mempertahankan posisinya di tengah-tengah persaingan global yang sedang terjadi. Hal ini tentunya menuntut suatu solusi yang menjamin eksistensi perusahaan agar dapat bersaing dan mempertahankan posisinya. Salah satu solusi yang dapat dilakukan adalah dengan melakukan peningkatan produktivitas. Dalam rangka peningkatan mutu serta pelayanan terhadap pelanggan setiap perusahaan sebaiknya memikirkan cara untuk dapat meningkatkan produktivitasnya. Hal ini penting karena dengan meningkatkan produktivitasnya akan berdampak pada peningkatan keuntungan perusahaan tanpa menaikkan harga jual dari produk yang di tawarkan [1].

\section{Algoritma}

Algoritma adalah langkah-langkah yang logis dan terstruktur untuk menyelesaikan suatu permasalahan. Yang dimaksud logis dalam hal ini adalah bahwa langkah yang diambil masuk akal dan dapat dinilai benar atau salahnya. Sedangkan terstruktur memiliki pengertian bahwa langkah tersebut susunan sesuai urutan kejadian atau waktu [5].

Algoritma Particle Swarm Optimization (PSO) diperkenalkan oleh Kennedy dan Eberhart pada tahun 1995, proses algoritmanya diinspirasi oleh perilaku sosial dari binatang, seperti sekumpulan burung dalam suatu swarm.

Particle Swarm Optimization (PSO) adalah salahsatu dari teknik komputasi evolusioner, yang mana populasi pada PSO didasarkan pada penelusuran algoritma dan diawali dengan suatu populasi yang random yang disebut dengan particle. Berbeda dengan teknik komputasi evolusionerlainnya, setiap particle di dalam PSO juga berhubungan dengan suatu velocity. Particle-particle tersebut bergerak melalui penelusuran ruang dengan velocity yang dinamis yang disesuaikan menurut perilaku historisnya. Oleh karena itu, particle-particle mempunyai kecenderungan untuk bergerak ke area penelusuran yang lebih baik setelah melewati proses penelusuran [3].

Particle Swarm Optimization (PSO) mempunyai kesamaan dengan genetic algorithm yang mana dimulai dengan suatu populasi yang random dalam bentuk matriks. Namun PSO tidak memiliki operatorevolusi yaitu crossover dan mutasi seperti yang ada pada genetic algorithm. Baris pada matriks disebut particle atau dalam genetic algorithm sebagai kromosom yang terdiri dari nilai suatu variable. Setiap particle berpindah dari posisinya semula keposisi yang lebih baik dengan suatu velocity . Pada algoritma PSO vektor velocity diupdate untuk masing-masing particle kemudian menjumlahkan vektor velocity tersebut ke posisi particle. Update velocity dipengaruhi oleh kedua solusi yaitu global best yang berhubungan dengan biaya yang paling rendah yang pernah diperoleh dari suatu particle dan solusi local best yang berhubungan dengan biaya yang paling rendah pada populasi awal.

Jika solusi local best mempunyai suatu biaya yang kurang dari biaya solusi global yang ada, maka solusi local best menggantikan solusi global best. Kesederhanaan 
algoritma dan performansinya yang baik, menjadikan PSO telah menarik banyak perhatian di kalangan para peneliti dan telah di aplikasikan dalam berbagai persoalan optimisasi sistem tenaga seperti economic dispatch, design kontrol PID pada sistem AVR, kontrol tegangan dan daya reaktif, unit commitment dan lain sebagainya. PSO telah populer menjadi optimisasi global dengan sebagian besar permasalahan dapat diselesaikan dengan baik di mana variabel-variabelnya adalah bilangan riil.

Algoritma PSO meniru perilaku sosial organisme ini. Perilaku sosial terdiri dari tindakan individu dan pengaruh dari individu-individu lain dalam suatu kelompok. Kata partikel menunjukkan, misalnya, seekor burung dalam kawanan burung. Setiap individu atau partikel berperilaku secara terdistribusi dengan cara menggunakan kecerdasannya (intelligence) sendiri dan juga dipengaruhi perilaku kelompok kolektifnya. Dengan demikian, jika satu partikel atau seekor burung menemukan jalan yang tepat atau pendek menuju ke sumber makanan, sisa kelompok yang lain juga akan dapat segera mengikuti jalan tersebut meskipun lokasi mereka jauh di kelompok tersebut [6].

Metode optimasi yang didasarkan pada swarm intelligence ini disebut algoritma behaviorally inspired sebagai alternatif dari algoritma genetika, yang sering disebut evolution-based procedures. Algoritma PSO ini awalnya diusulkan oleh [1]. Dalam konteks optimasi multivariabel, kawanan diasumsikan mempunyai ukuran tertentu atau tetap dengan setiap partikel posisi awalnya terletak di suatu lokasi yang acak dalam ruang multidimensi. Setiap partikel diasumsikan memiliki dua karakteristik: posisi dan kecepatan. Setiap partikel bergerak dalam ruang/space tertentu dan mengingat posisi terbaik yang pernah dilalui atau ditemukan terhadap sumber makanan atau nilai fungsi objektif. Setiap

partikel menyampaikan informasi atau posisi bagusnya kepada partikel yang lain dan menyesuaikan posisi dan kecepatan masing-masing berdasarkan informasi yang diterima mengenai posisi yang bagus.

Sebagai pembuktian, misalnya perilaku burung-burung dalam dalam kawanan burung. Meskipun setiap burung mempunyai keterbatasan dalam hal kecerdasan, biasanya ia akan mengikuti kebiasaan (rule) seperti berikut :
1. Seekor burung tidak berada terlalu dekat dengan burung yang lain

2.Burung tersebut akan mengarahkan terbangnya ke arah rata-rata keseluruhan burung

3. Akan memposisikan diri dengan rata-rata posisi burung yang lain dengan menjaga sehingga jarak antar burung dalam kawanan itu tidak terlalu jauh.

Dengan demikian perilaku kawanan burung akan didasarkan pada kombinasi

dari 3 faktor simpel berikut:

1. Kohesi - terbang bersama

2. Separasi - jangan terlalu dekat

3. Penyesuaian(alignment) - mengikuti arah bersama

Jadi PSO dikembangkan dengan berdasarkan pada model berikut:

1. Ketika seekor burung mendekati target atau makanan (atau bisa mnimum atau maximum suatu fungsi tujuan) secara cepat mengirim informasi kepada burung-burung yang lain dalam kawanan tertentu

2. Burung yang lain akan mengikuti arah menuju ke makanan tetapi tidak secara langsung

3. Ada komponen yang tergantung pada pikiran setiap burung, yaitu memorinya tentang apa yang sudah dilewati pada waktu sebelumnya.

Model ini akan disimulasikan dalam ruang dengan dimensi tertentu dengan sejumlah iterasi sehingga di setiap iterasi, posisi partikel akan semakin mengarah

ke target yang dituju (minimasi atau maksimasi fungsi). Ini dilakukan hingga maksimum iterasi dicapai atau bisa juga digunakan kriteria penghentian yang

lain.Implementasi PSO akan diMisalkan mempunyai fungsi berikut:

\section{$\min \mathbf{f}(\mathbf{x})$}

$$
\text { Dimana } \mathbf{X}^{(\mathbf{B})} \leq \mathbf{X} \leq \mathbf{X}^{(\mathbf{A})}
$$

dimana $X^{(B)}$ adalah batas bawah dan $X^{(A)}$ adalah batas atas dari X ProsedurPSO dapat dijabarkan dengan langkah-langkah sebagai berikut [2]:

1. Asumsikan bahwa ukuran kelompok atau kawanan (jumlah partikel) adalah N. Untuk mengurangi jumlah evaluasi fungsi yang diperlukan untuk menemukan solusi, sebaiknya ukuran $\mathrm{N}$ tidak terlalu besar, tetapi juga tidak terlalu kecil,agar ada banyak kemungkinan posisi 
menuju solusi terbaik atau optimal. Jika terlalu kecil, sedikit kemungkinan menemukan posisi partikel yang baik. Terlalu besar juga akan membuat perhitungan jadi panjang. Biasanya digunakan ukuran kawanan adalah 20 sampai 30 partikel.

2. Bangkitkan populasi awal $X$ dengan rentang $X^{(B)}$ dan $X^{(A)}$ secara random sehingga didapat. $X_{1}, X_{2}, \ldots, X_{N}$ Setelah itu, untuk mudahnya,partikel j dan kecepatannya pada iterasi $i$ dinotasikan sebagai $X_{j}^{(i)}$ dan $V_{j}^{(i)}$ Sehingga partikel-partikel awal ini akan menjadi $X_{1}(0), X_{2}(0), \ldots, X_{N}(0)$. Vektor $X_{j}(0),(\mathrm{j}=1,2$, ...,N) disebut partikel atau vektor koordinat dari partikel. (seperti kromosom dalam algoritma genetika). Evaluasi nilai fungsi tujuan untuk setiap partikel dan nyatakan dengan

$$
\left.f X_{1}(0)\right], f\left[X_{2}(0)\right], \ldots, f\left[X_{N}(0)\right]
$$

3. Hitung kecepatan dari semua partikel. Semua partikel bergerak menuju titik optimal dengan suatu kecepatan. Awalnya semua kecepatan dari partikel diasumsikan sama dengan nol. Set iterasi $\mathrm{i}=1$.

4. Pada iterasi ke-i, temukan 2 parameter penting untuk setiap partikel j yaitu:

(a) Nilai terbaik sejauh ini dari $X_{j}$ (i) (koordinat partikel j pada iterasi i) dan nyatakan sebagai $P_{b e s t, j}$, dengan nilai fungsi obyektif paling rendah (kasus minimasi) , $f\left[X_{j}(\mathrm{i})\right]$, yang ditemui sebuah partikel j pada semua iterasi sebelumnya. Nilai terbaik untuk semua partikel $X_{j}(\mathrm{i})$ yang ditemukan sampai iterasi ke-i, $G_{\text {best }}$,dengan nilai fungsi tujuan paling kecil / minimum diantara semua partikel untuk semua iterasi sebelumnya, $f\left[X_{j}(i)\right]$

(b) Hitung kecepatan partikel j pada iterasi ke i dengan rumus sebagai berikut:

$$
\begin{gathered}
V_{j}(i)=V_{j}(i-1)+c_{1} r_{1}\left[P_{b e s t, j}-x_{j}(i-1)+\right. \\
c_{2} r_{2}\left[G_{\text {best }}-x_{j}(i-1)\right], j=1,2, \ldots, N
\end{gathered}
$$

dimana $C_{1}$ dan $C_{2}$ masing-masing adalah learning rates untuk kemampuan individu (cognitive) dan pengaruh sosial (group), dan $r_{1}$ dan $r_{2}$ bilangan random yang berdistribusi uniforml dalam interval 0 dan 1. Jadi parameters $C_{1}$ dan $C_{2}$ menunjukkan bobot dari memory (position) sebuah partikel terhadap memory (posisi) dari kelompok(swarm). Nilai dari $c_{1}$ dan $C_{2}$ biasanya adalah 2 sehingga perkalian $c_{1} r_{1}$ dan $c_{2} r_{2}$ memastikan bahwa partikel-partikel akan mendekati target sekitar setengah selisihnya.

(c) Hitung posisi atau koordinat partikel j pada iterasi kei dengan cara

$$
X_{j}(i)=X_{j}(i-1)+V_{j}(i) ; j=1,2, \ldots, N
$$

Evaluasi nilai fungsi tujuan untuk setiap partikel dan nyatakan sebagai

$$
f\left[X_{1}(i), f\left[X_{2}(i)\right], \ldots, f\left[X_{N}(i)\right]\right.
$$

5. Cek apakah solusi yang sekarang sudah konvergen. Jika posisi semua partikel menuju ke satu nilai yang sama, maka ini disebut konvergen. Jika belum konvergen maka langkah 4 diulang dengan memperbarui iterasi $\mathrm{i}=\mathrm{i}+1$, dengan cara menghitung nilai baru dari $P_{b e s t, j}$ dan $G_{\text {best }}$. Proses iterasi ini dilanjutkan sampai semua partikel menuju ke satu titik solusi yang sama. Biasanya akan ditentukan dengan kriteria penghentian (stopping criteria), misalnya jumlah selisih solusi sekarang dengan solusi sebelumnya sudah sangat kecil.

Misalkan kita mempunyai persoalan optimasi dengan satu variabel sebagai berikut:

$$
\begin{gathered}
f(x)=(100-x)^{2} \\
\text { dimana } 60 \leq x \leq 120
\end{gathered}
$$

1. Tentukan jumlah partikel $\mathrm{N}=4$ Tentukan populasi awal secara random, misalkan didapat

$$
\begin{aligned}
& x_{1}(0)=80, \\
& x_{2}(0)=90, \\
& x_{3}(0)=110, \\
& x_{4}(0)=75 .
\end{aligned}
$$


2. Evaluasi nilai fungsi tujuan untuk setiap partikel $x_{j}(0)$ untuk $j=1,2,3,4$. dan nyatakan dengan

$f_{1}=f(80)=400$,

$f_{2}=f(90)=100$,

$f_{3}=f(110)=100$,

$f_{4}=f(75)=625$.

3. Tentukan kecepatan awal $v_{1}(0)=v_{2}(0)=v_{3}(0)=v_{4}(0)$ $=0$. Tentukan iterasi $\mathrm{i}=1$; Lalu ke langkah nomer 4 .

4. Temukan $P_{\text {best }}, 1=80, P_{\text {best }}, 2=90, P_{\text {best }}, 3=110$, $P_{\text {best }}, 4=75, G_{\text {best }}=90$. Hitung $v(\mathrm{j})$ dengan $c_{1}=c_{2}=$ 1. Misalkan nilai random yang didapat, $r_{1}=0.4, r_{2}=$ 0.5 , dengan rumus $v_{j}(\mathrm{i})=v_{j}(\mathrm{i}-1)+c_{1} c_{2}\left[P_{b e s t, j}\right.$ $\left.x_{j}(\mathrm{i}-1)\right]+c_{1} c_{2}\left[G_{\text {best }}-x_{j}(\mathrm{i}-1)\right]$ diperoleh

$v_{1}(1)=0+0.4(80-80)+0.5(90-80)=5$

$v_{2}(1)=0+0.4(90-90)+0.5(90-90)=0$

$v_{3}(1)=0+0.4(110-110)+0.5(90-110)=-10$

$v_{4}(1)=0+0.4(75-75)+0.5(90-75)=7.5$

Sedangkan untuk nilai $\mathrm{x}$ adalah

$x_{1}(1)=80+5=85$

$x_{2}(1)=90+0=90$

$x_{3}(1)=110-10=100$

$x_{4}(1)=75+7.5=82.5$

5. Evaluasi nilai fungsi tujuan sekarang pada partikel $x_{j}(1)$,

$f_{1}(1)=f(85)=225$,

$f_{2}(1)=f(90)=100$,

$f_{3}(1)=f(100)=0$,

$f_{4}(1)=f(82.5)=306.25$.

Sedangkan pada iterasi sebelumnya kita dapatkan

$f_{1}(0)=f(80)=400$

$f_{2}(0)=f(90)=100$,

$f_{3}(0)=f(110)=100$,

$f_{4}(0)=f(75)=625$.

Nilai dari $f$ dari iterasi sebelumnya tidak ada yang lebih baik sehingga
$P_{\text {best }}$ untuk masing-masing partikel sama dengan nilai x-nya. $G_{\text {best }}=100$.

Cek apakah solusi $\mathrm{x}$ sudah konvergen, dimana nilai $\mathrm{x}$ saling dekat. Jika tidak,

tingkatkan ke iterasi berikutnya $i=2$. Lanjutkan ke langkah 4.

1. $P_{\text {best }, 1}=85, P_{\text {best }, 2}=90, P_{\text {best }, 3}=100, P_{\text {best }, 4}=$ $82.5, G_{\text {best }}=100$ Hitung kecepatan baru dengan $\mathrm{r} 1=0.3$ dan $r=0.6$ (ini hanya sekedar contoh untuk menjelaskan penghitungan, dalam implementasi angka ini dibangkitkan secara random).

$v_{1}(2)=5+0.3(85-85)+0.6(100-85)=14$

$v_{2}(2)=0+0.3(90-90)+0.6(100-90)=6$.

$v_{3}(2)=-10+0.3(100-100)+0.6(100-100)=-10$

$v_{4}(2)=7.5+0.3(82.5-82.5)+0.6(100-82.5)=18$

Sedangkan untuk nilai $\mathrm{x}$ adalah

$x_{1}(2)=85+14=99$

$x_{2}(2)=90+6=96$

$x_{3}(2)=100-10=90$

$x_{4}(2)=82.5+18=100.5$

2. Evaluasi nilai fungsi tujuan sekarang pada partikel $x_{j}(2)$,

$f_{1}(2)=f(99)=1$,

$f_{2}(2)=f(96)=16$,

$f_{3}(2)=f(90)=100$

$f_{4}(2)=f(100.5)=0.25$.

Jika dibandingkan dengan nilai $f$ dari iterasi sebelumnya, ada nilai yang lebih baik dari nilai $f$ sekarang yaitu $f_{3}(1)$ $=0$, sehingga $P_{\text {best }}$ untuk partikel 3 sama dengan 100, dan $G_{\text {best }}$ dicari dari $\min \{1,16,0,0.25\}=0$ yang dicapai pada $x_{3}(1)=100$. Sehingga untuk iterasi berikutnya $P_{\text {best }}=(99,96,100,100.5)$ dan $G_{\text {best }}=$ 100 .

Cek apakah solusi sudah konvergen, dimana nilai $\mathrm{x}$ saling dekat. Jika tidak konvergen, set $\mathrm{i}=3$, masuk ke iterasi berikutnya. Lanjutkan ke langkah berikutnya dengan menghitung kecepatan $\mathrm{v}$ dan ulangi langkah-langkah selanjunya sampai mencapai konvergen. 


\section{III.Metode Penelitian}

Model pengembangan sistem ini menggunakan model incremental

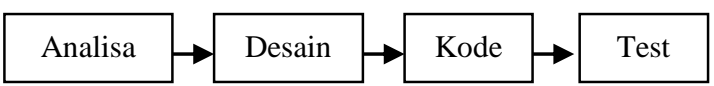

A. Analisa Data

Pada penelitian ini penulis menggunakan teknik pengumpulan data dengan cara wawancara, observasi dan studi pustaka untuk mendapatkan data-data yang digunakan dalam penelitian.

B. Desain Sistem

Dalam membangun sebuah aplikasi dibutuhkan adanya sebuah alur. Alur merupakan arah jalannya sebuah aplikasi yang telah ditentukan agar aplikasi tersebut jelas kemana arah perjalanannya.

Untuk lebih jelas mengenai alur dari aplikasi algoritma Particle swarm Optimization dalam optimalisasi penjualan motor dapat dilihat pada Gambar 1:

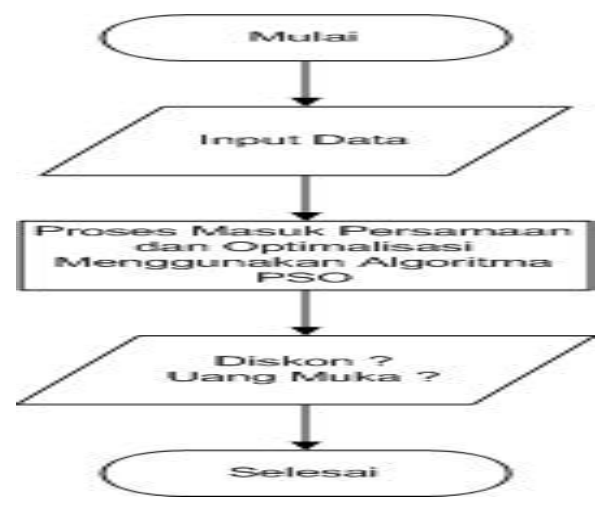

Gambar 1. Alur Aplikasi Algoritma PSO

\section{IV.HASIL Dan PEMbahasan}

A. Hasil

Tampilan Form Password adalah form yang pertama kali muncul, Sebelum user menggunakan program optimalisasi penjualan motor menggunakan algoritma particle swarm optimization, User harus memasukkan nama dan password dengan benar, jika user memasukkan nama dan password tidak benar, maka program aplikasi akan memberikan informasi jika password yang dimasukkan salah.
Apabila Password yang dimasukkan tidak benar, maka aplikasi tidak akan bisa dibuka dan digunakan untuk melakukan proses data. Didalam Form ini, terdapat 2 tombol yaitu login dan cancel.seperti pada gambar berikut ini :

1. Menu Login

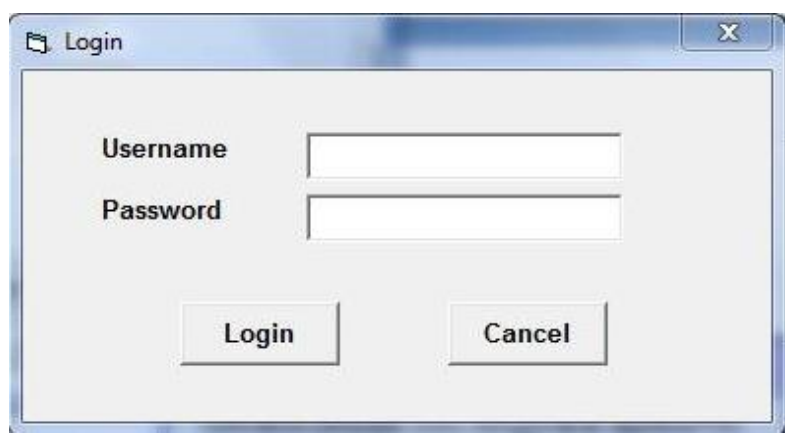

Gambar 2. Menu Login

\section{Tampilan Menu Utama}

Form Menu Utama Merupakan Form setelah form password. Jika user telah memasukkan nama dan password dengan benar maka aplikasi akan menampilkan Form Menu Utama. Dimana didalam form tersebut user akan memilih tombol-tombol yang diperlukan sesuai kebutuhan.

Berikut ini adalah tampilan form menu utama dari Program Optimalisasi penjualan Motor menggunakan Algoritma Particle Swarm Optimization seperti gambar dibawah ini :

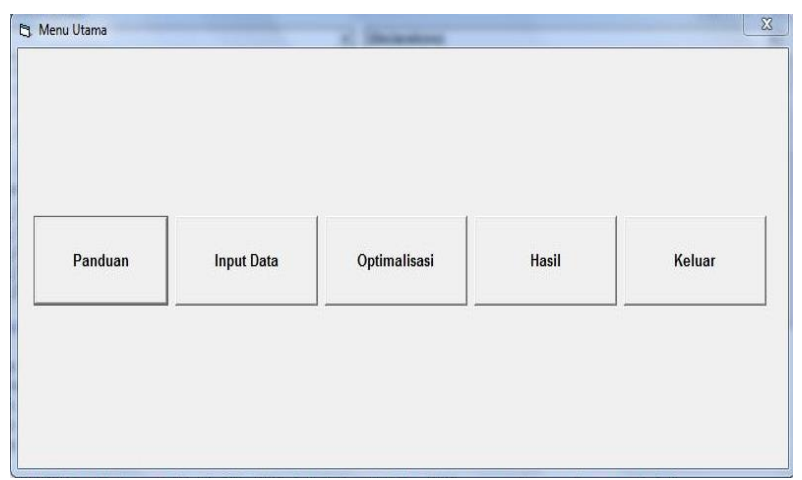

Gambar 3. Menu Utama

3. Tampilan Menu Panduan 


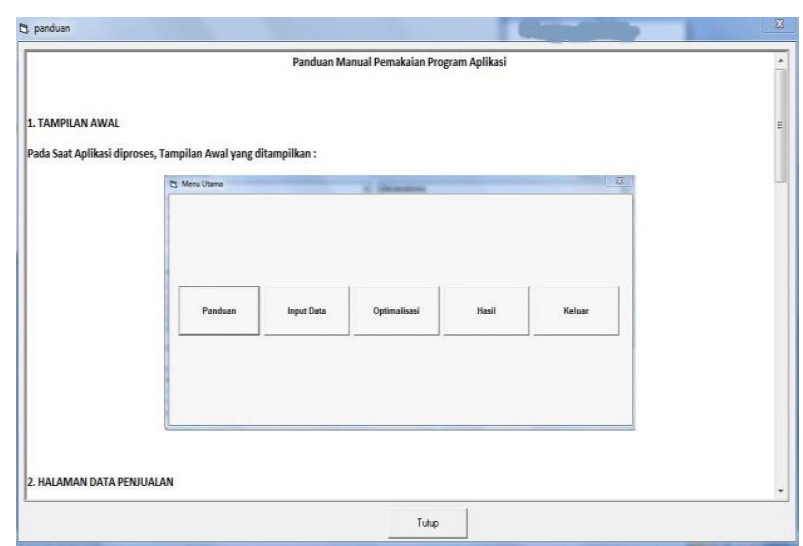

Gambar 4. Menu Panduan

\section{Tombol Input Data}

Tombol ini berfungsi untuk menampilkan input data, dengan memasukkan data dari penjualan sebelumnya berdasarkan ID penjualan, Periode, Biaya Promosi, Diskon, Uang Muka dan penjualan. Apabila data yang dimasukkan kurang maka user dapat memasukkan data yang baru dengan cara memilih tombol tambah, dan apabila data yang dimasukkan salah, user dapat merubah data tersebut dengan memilih tombol ubah dan masukkan ID data yang salah tersebut. Setelah data yang dimasukkan benar maka disimpan dengan tombol Simpan. Berikut ini adalah tampilan dari tombol input data.

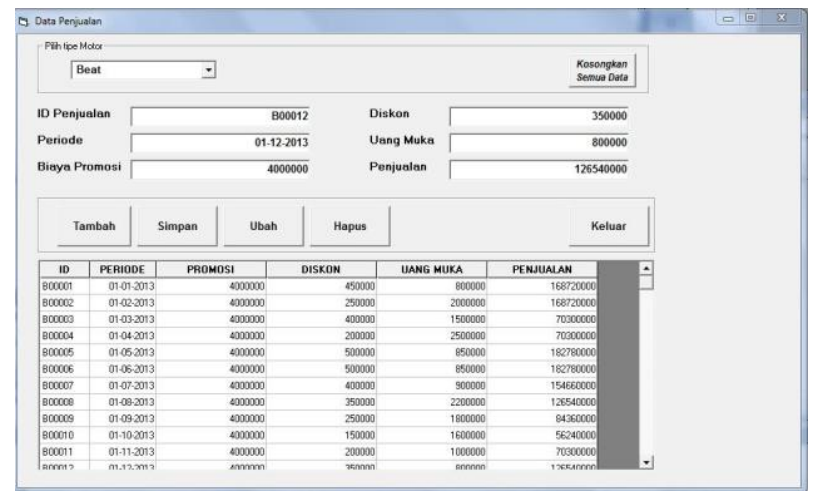

Gambar 5. Menu Input Data

\section{B. Pembahasan}

Tombol ini berfungsi untuk menampilkan optimalisasi penjualan motor dengan menggunakan algoritma particle swarm optimization, dengan cara memasukkan parameterparameter dari algoritma Particle Swarm Optimization dan memilih motor apa yang ingin di optimalisasikan. Setelah parameter-parameter tersebut dimasukkan, maka pilih proses, setelah proses dilakukan akan keluar hasil optimalisasi penjualan motor dengan menggunakan algoritma Particle swarm optimization, maka diperoleh iterasi mana yang harus dipilih, dan untuk menentukan diskon, dan uang muka yang akan digunakan kedepan serta perkiraan besar total penjualan selama 12 bulan kedepan.

Berikut Tampilan proses optimalisasi seperti gambar dibawah ini :

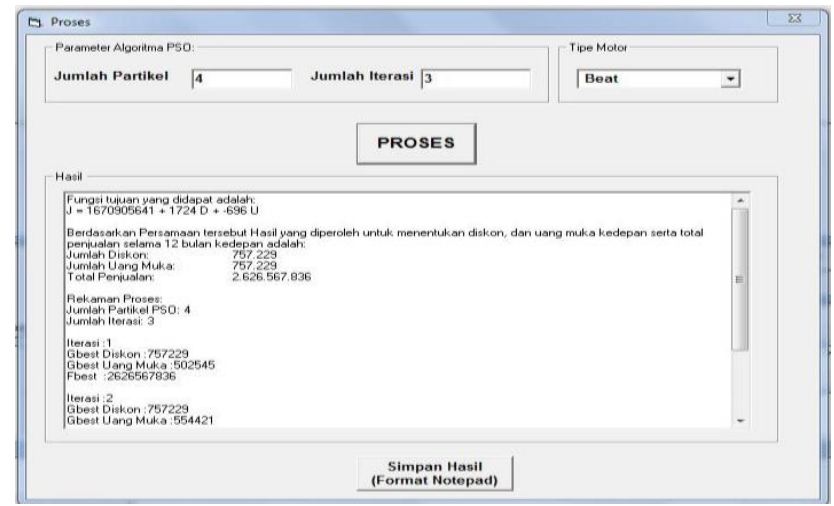

Gambar 6. Proses Optimalisasi

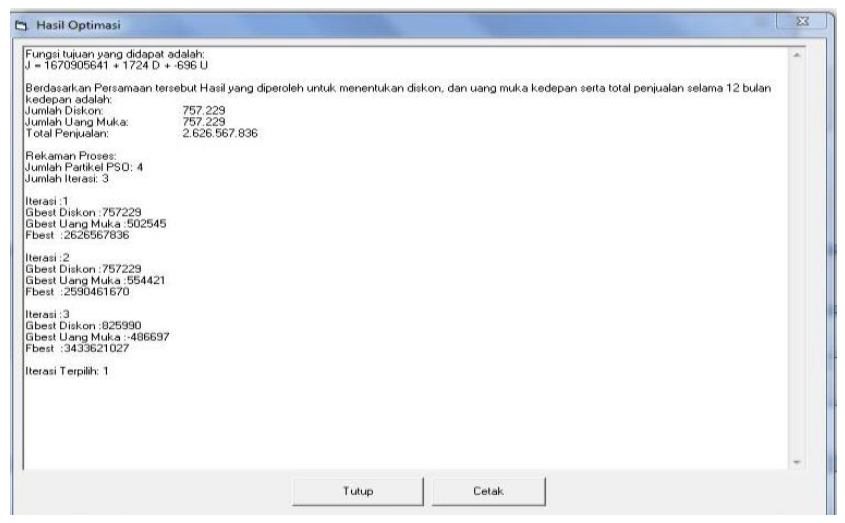

Gambar 7. Hasil Optimalisasi

\section{KESIMPULAN DAN SARAN}

\section{A. Kesimpulan}

Dari hasil analisa, perancangan, pengujian dan implementasi program dengan menggunakan algoritma Particle swarm optimization yang telah dilakukan terhadap aplikasi dapat disimpulkan bahwa dapat diketahui besaran diskon dan uang muka yang akan digunakan dapat meningkatkan penjualan kedepan dan perkiraan besar total penjualan selama 12 bulan kedepan.

\section{B. Saran}

Penelitian yang dilakukan tentunya tidak terlepas dari kekurangan dan kelemahan. Oleh karena itu, untuk kebaikan 
pengembangan sistem lebih lanjut, maka penulis menyarankan beberapa hal diantaranya :

1. Dikarenakan ilmu pengetahuan terus berkembang dan ditemukannya hal-hal baru maka aplikasi optimalisasi ini dapat dikembangkan dengan metode yang lain sehingga mendapatkan perbandingan metode mana yang cocok dalam pengoptimalan peningkaatan penjualan motor.

2. Interface (tampilan) sistem yang dibangun masih tampak sederhana, sehingga dapat dikembangkan lebih menarik dengan dilengkapi multimedia (suara dan gambar) maupun animasi.

\section{DAFTAR PUSTAKA}

[1] Djadna, Taufik \& Ida Bagus Dharma Yoga Santosa. Peningkatan Produktivitas produksi kecap pada Lini Perakitan Dengan Pendekatan Lean Production.EJurnal Agroindustri Indonesia Juli 2012, Vol.1 No.1, P 1-10, ISSN: 2252 : 3324. Didownload Pada tanggal 8 mei 2013.

[2] Yulianti, Eva dan Tauvan Rusyiatno.Rekayasa Perangkat Lunak Penjualan pulsa Electric Berbasis Sms Menggunakan Visual Basic 6.0.Jurnal TEKNOIF,Vol.1,No.1, Edisi April 2013, Didownload pada tanggal 28 Juni 2014.

[3] Tuegeh, Maickel, dkk. 2009. Modified Improved Particle swarm optimization for optimal Generator Scheduling. Seminar Nasional Aplikasi Teknologi Informasi 2009 (SNATI 2009), Yogyakarta, 20 Juni 2009. Diambil pada tanggal 8 Mei 2013.

[4] Munadi, Fandi Ahmad. Analisis Strategi Pemasaran untuk Meningkatkan Penjualan Kendaraan Motor Pada CV Turangga Mas Motor. Jurusan Ekonomi Manajemen, Fakultas Ekonomi, Universitas Gunadarma. Didownload pada tanggal 4 mei 2013.

[5] Wahyudi, Eko Nur. Algoritma dan Pemograman Format laporan dengan Pascal. Jurnal Teknologi Informasi DINAMIK Volume XII, No.1, Januari 2007: 22-30. Didownload pada tanggal 28 Juni 2014.

[6] Santosa, B. Tutorial particle Swarm optimization. Makalah : Teknik Industri, ITS, Kampus ITS,
Sukolilo Surabaya. Didownload tanggal 27 September 2013. 